\title{
Kesepadanan Dalam Penerjemahan Kosakata Bermuatan Budaya Pada Anime Sen To Chihiro No Kamikakushi
}

\author{
Ni Kadek Purwantini ${ }^{\left.{ }^{*}\right)}$, Ni Nengah Suartini ${ }^{2)}$, \\ Kadek Eva Krishna Adnyani ${ }^{3)}$ \\ PS Pendidikan Bahasa Jepang, Universitas Pendidikan Ganesha, \\ Singaraja-Bali \\ ${ }^{1}$ [purwantini1999@gmail.com], ${ }^{2}$ [nnsuartini@undiksha.ac.id] \\ 3 [krishna.adnyani@undiksha.ac.id]
}

\begin{abstract}
Abstrak
Penelitian ini bertujuan untuk mendeskripsikan kesepadanan penerjemahan kosakata bermuatan budaya Jepang ke dalam bahasa Indonesia pada anime Sen to Chihiro no Kamikakushi serta prosedur penerjemahan yang diterapkan dalam menerjemahkan BSu (bahasa sumber) ke dalam BSa (bahasa sasaran). Penelitian ini merupakan penelitian deskriptif kualitatif dengan menggunakan kartu data. Teori yang digunakan adalah teori kategori kosakata bermuatan budaya menurut Newmark (1988), teori kesepadanan menurut Nida dan Taber (1974), serta teori prosedur penerjemahan menurut Newmark (1988). Terdapat 38 data yang merupakan kosakata bermuatan budaya Jepang serta terjemahannya dalam bahasa Indonesia. Hasil penelitian menunjukkan bahwa 30 data mencapai kesepadanan dan 8 data tidak mencapai kesepadanan. Kemudian, terdapat 7 prosedur penerjemahan yang diterapkan, yaitu padanan budaya, sinonim, netralisasi, penjelasan tambahan, modulasi, transposisi, dan reduksi dan ekspansi. Padanan budaya dan sinonim menjadi prosedur yang paling banyak diterapkan.
\end{abstract}

Kata kunci: kesepadanan terjemahan, kosakata budaya, prosedur penerjemahan

\begin{abstract}
This study aims to describe the equivalence of translating Japanese cultural terms into Indonesian in the anime Sen to Chihiro no Kamikakushi and the translation procedures applied in translating $S L$ (source language) into TL (target language). This research is a qualitative descriptive study using data cards. The theory used is the category of cultural terms by Newmark (1988), the theory of equivalence by Nida and Taber (1974), and the theory of translation procedures by Newmark (1988). There are 38 data which are Japanese cultural terms and its translations in Indonesian. The results showed that 30 data reached equivalence and 8 data did not reach equivalence. Then, there are 7 translation procedures applied, including cultural equivalent, synonym, neutralization, additional explanation, modulation, transposition, and reduction and expansion. Cultural equivalence and synonyms are the most frequently applied procedures.
\end{abstract}

Keywords : translation equivalence, cultural terms, translation procedures.

\section{Pendahuluan}

Penerjemahan adalah suatu proses pengalihan makna sebuah teks ke dalam bahasa lainnya sesuai dengan maksud yang ingin disampaikan oleh penulis asli teks tersebut (Newmark, 1988:5). Dalam menerjemahkan suatu bahasa, penerjemah berperan sebagai 
jembatan untuk menyampaikan pesan yang terdapat di dalam BSu kepada pembaca BSa, sehingga dibutuhkan kemampuan untuk dapat memahami maksud dari penulis asli teks.

Perbedaan kebudayaan yang terdapat pada BSu dan BSa dapat menyebabkan terjadinya hambatan dalam proses penerjemahan. Menurut Catford (1965:264), faktor kebudayaan menjadi salah satu hambatan yang paling sering timbul dalam proses penerjemahan, karena adanya istilah yang terdapat dalam kebudayaan BSu tidak dikenal dalam kebudayaan BSa. Hal tersebut membuat penerjemahan menjadi hal yang tidak mudah karena harus mencari kata yang sepadan berkenaan dengan kebudayaan BSu dan kebudayaan BSa. Kesepadanan dalam penerjemahan sangat dipengaruhi oleh pemilihan prosedur penerjemahan yang tepat. Penerapan prosedur penerjemahan yang tepat dapat memudahkan penerjemah dalam upaya mencapai kesepadanan terjemahan.

Saat ini penerjemahan tidak hanya berupa alih bahasa tulisan ke dalam bahasa tulisan lainnya, melainkan juga merambah pada penerjemahan audiovisual, salah satunya bisa ditemukan pada penerjemahan subtitle anime. Sebagian besar anime masih berbasis pada bahasa Jepang, sehingga seringkali terdapat istilah-istilah budaya dalam bahasa Jepang yang cukup sulit diterjemahkan ke dalam bahasa lainnya karena adanya perbedaan kebudayaan.

Pada penelitian sebelumnya, sudah banyak penelitian mengenai penerjemahan kosakata bermuatan budaya khususnya pada penerjemahan novel. Dalam menerjemahkan novel, penerjemah tidak dibatasi pada jumlah karakter sehingga memudahkan untuk memilih padanan kata. Sedangkan dalam penerjemahan subtitle, khususnya terkait kosakata bermuatan budaya, penerjemah harus menyesuaikan dengan ruang layar dan waktu membaca subtitle yang singkat, sekaligus memilih padanan kata yang tepat karena adanya istilah budaya yang sulit untuk diterjemahkan. Hal tersebut menjadi tantangan yang tak mudah bagi penerjemah subtitle karena harus meringkas terjemahan tanpa menghilangkan pesan yang ada dalam BSu.

Berdasarkan paparan di atas, maka perlu adanya penelitian terkait penerjemahan subtitle pada anime, khususnya terkait kosakata bermuatan budaya. Oleh karena itu, dalam penelitian ini akan mengkaji lebih dalam mengenai kesepadanan dalam penerjemahan kosakata bermuatan budaya serta prosedur yang digunakan sebagai upaya mencapai kesepadanan dalam menerjemahkan kosakata bermuatan budaya Jepang ke dalam bahasa Indonesia. Data penelitian diambil dari anime berjudul Sen to Chihiro no 
Kamikakushi, salah satu anime terpopuler dan menjadi salah satu karya monumental dari Studio Ghibli, beserta dengan terjemahannya yang berupa subtitle dalam bahasa Indonesia

Berdasarkan pernyataan diatas, dapat dirumuskan permasalahan sebagai berikut.

a. Apakah penerjemahan kosakata bermuatan budaya Jepang dalam anime Sen to Chihiro no Kamikakushi sudah sepadan dengan terjemahannya dalam bahasa Indonesia?

b. Bagaimanakah prosedur penerjemahan yang diterapkan dalam penerjemahan kosakata bermuatan budaya Jepang ke dalam bahasa Indonesia dalam anime Sen to Chihiro no Kamikakushi?

Secara umum penelitian ini diharapkan dapat mendeskripsikan kesepadanan penerjemahan kosakata bermuatan budaya Jepang ke dalam bahasa Indonesia pada anime Sen to Chihiro no Kamikakushi serta prosedur penerjemahan yang diterapkan dalam penerjemahan tersebut. Untuk menjawab rumusan masalah tersebut, kesepadanan terjemahan dianalisis menggunakan teori kesepadanan Nida dan Taber (1974) dan prosedur penerjemahannya dianalisis menggunakan teori prosedur penerjemahan Newmark (1988).

\section{Metode dan Teori}

\subsection{Metode Penelitian}

Penelitian ini menggunakan metode simak dan teknik catat untuk mengumpulkan data. Pada tahap analisis data, penelitian ini menggunakan metode deskriptif komparatif dengan bantuan kamus ekabahasa kokugo jiten daring (dictionary.goo.ne.jp) dan KBBI daring (kbbi.web.id) untuk membandingkan makna pada data yang memuat BSu dan BSa.

\subsection{Teori}

Teori kesepadanan Nida dan Taber (1974) dan teori prosedur penerjemahan Newmark (1988) digunakan pada penelitian ini untuk menganalisis masalah. Teori kesepadanan Nida dan Taber (1974) digunakan untuk menentukan kedua makna pada data yang memuat BSu dan BSa sudah sepadan atau tidak sepadan. Kemudian setelah data dibagi menjadi dua kelompok, yaitu data yang sepadan dan tidak sepadan, masing- 
masing data tersebut dilakukan analisis terkait prosedur penerjemahan yang diterapkan dengan menggunakan teori prosedur penerjemahan Newmark (1988).

\section{Kajian Pustaka}

Beberapa penelitian tentang penerjemahan kosakata bermuatan budaya telah dilakukan sebelumnya oleh Prabawati, dkk (2015), Zulkarnaein (2018), dan Muryati dan Astuti (2020). Hasil penelitian Prabawati, dkk (2015) menunjukkan prosedur penerjemahan literal paling banyak diterapkan dalam penerjemahan kosakata bermuatan budaya pada novel Negeri 5 Menara. Kemudian, hasil penelitian Zulkarnaein (2018) menunjukan bahwa penerjemahan kosakata bermuatan budaya pada novel Oda Nobunaga paling banyak mencapai kesepadanan dengan penerapan teknik transposisi dan padanan budaya. Terakhir, hasil penelitian Muryati dan Astuti (2020) menunjukkan bahwa strategi pola khusus-umum paling banyak diterapkan dalam menerjemahkan kata bermuatan budaya Jawa Tengah ke dalam bahasa Jepang pada brosur dan booklet pariwisata. Beberapa referensi penelitian sebelumnya telah banyak menggunakan sumber data berupa novel maupun brosur. Subtitle sebagai sumber data masih sedikit ditemukan, khususnya penelitian tentang penerjemahan kosakata bermuatan budaya Jepang ke dalam bahasa Indonesia.

\section{Hasil dan Pembahasan}

Pada penelitian ini, dari 38 data yang mengandung kosakata bermuatan budaya Jepang serta terjemahannya dalam bahasa Indonesia, ditemukan 30 data yang sepadan dan 8 data yang tidak sepadan. Kemudian, ditemukan 7 prosedur penerjemahan yang diterapkan dalam penerjemahan tersebut.

\subsection{Terjemahan Sepadan}

\section{a. Padanan Budaya}

(1) BSu：あいつは湯婆婆の手先だから気をつけな。 Aitsu wa Yubaba no tesakidakara ki o tsukena. BSa : Dia kaki tangan Yubaba. Hati-hatilah.

(Sen to Chihiro no Kamikakushi, 00.42.55-00.42.58)

Dalam dictionary.goo.ne.jp, pengertian tesaki adalah:

1. 手の先の部分。指先。

'Bagian dari ujung tangan. Ujung jari.' 


\section{2. 手下となって使われる者。}

'Orang yang digunakan untuk menjadi bawahan.'

Pada data di atas, kata tesaki disepadankan menjadi kaki tangan dalam BSa. Dalam KBBI daring, pengertian kaki tangan adalah kaki dan tangan, seseorang yang diperalat untuk membantu orang lain.

Berdasarkan pengertian dari tesaki dan kaki tangan di atas, maka penerjemahan tersebut dapat dikatakan mencapai kesepadanan. Kedua kata tersebut memiliki makna yang sama, yaitu orang yang diperalat untuk membantu orang lain.

Prosedur penerjemahan yang diterapkan adalah padanan budaya, yaitu dengan menggunakan padanan kata berupa unsur kebudayaan yang terdapat dalam BSa (Newmark, 1988:82). Dalam kebudayaan BSa tidak mengenal istilah tesaki. Namun, penerjemah memilih kata yang terdapat dalam kebudayaan BSa yang maknanya sama dengan pengertian tesaki, yaitu kaki tangan. Frasa kaki tangan merupakan salah satu idiom dalam bahasa Indonesia yang berarti anak buah atau bawahan, sesuai dengan maksud kata dalam BSu.

\section{b. Sinonim}

(2) BSu : チビども、仕事だ! Chibidomo, shigotoda!

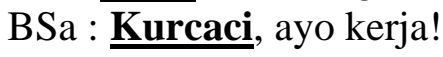

(Sen to Chihiro no Kamikakushi, 00.24.59-00.25.02)

Dalam dictionary.goo.ne.jp, pengertian chibi adalah:

小さいもの。からだの小さい人。また、年の幼い人や子供を親しみをこめてい う語。

'Sesuatu yang kecil. Orang bertubuh kecil. Juga kata yang familiar di kalangan anak kecil dan anak muda.'

Pada data di atas, kata chibi disepadankan menjadi kurcaci. Pengertian kata kurcaci dalam KBBI daring adalah makhluk halus yang konon berbentuk kecil, atau seseorang yang suka mengganggu. Dalam anime tersebut, sesuatu yang disebut sebagai chibi adalah makhluk halus berbentuk bulat kecil yang sebenarnya merupakan jelaga.

Berdasarkan pengertian dari chibi dan kurcaci di atas, maka data terjemahan dikatakan mencapai kesepadanan. Kedua kata tersebut memiliki makna yang serupa, yaitu makhluk halus yang kecil. 
Prosedur penerjemahan yang diterapkan adalah sinonim, yaitu dengan menggunakan kata yang mendekati padanan dalam BSa apabila penerjemah kesulitan menemukan padanan kata dari BSu yang lebih spesifik (Newmark, 1988:84). Penerjemah memilih kata dalam BSa yang dirasa memiliki makna paling dekat sesuai dengan pengertian chibi, yaitu makhluk kecil. Dalam BSa terdapat kata kurcaci yang memiliki makna yang mirip dengan pengertian chibi, sehingga kurcaci dianggap mampu untuk mewakili makna kata BSu pada BSa. Makna kata chibi tersebut juga tidak memiliki makna khusus atau terlalu spesifik, sehingga padanan kata yang dipilih tidak akan terlalu mempengaruhi makna yang dimaksud.

\section{c. Netralisasi}

(3) $\mathrm{BSu}$ : 八百万の神様たちが疲れを癒しにくるお湯屋なんだよ。 Yaoyorozu no kamisamatachi ga tsukare o iyashi ni kuru oyuyanandayo. BSa : Jutaan jin datang ke pemandian ini untuk menghilangkan penat.

(Sen to Chihiro no Kamikakushi, 00.36.29 - 00.36.35)

Oуиya berasal dari prefiks $o$ dan kata yuya. Prefiks $o$ berfungsi untuk menyopankan kata di depannya, yaitu kata yuya. Dalam dictionary.goo.ne.jp, pengertian kata yuya adalah:

1. 浴場のある建物。特に、社寺などに参籠するとき、斎戒沐浴 あるいは休息 するための建物。

'Sebuah bangunan dengan bak mandi. Khususnya ketika mengunjungi kuil dan sejenisnya, bangunan tersebut digunakan untuk mandi atau beristirahat.'

2. 料金を取って、入浴させる所。銭湯。風呂屋。

'Tempat untuk mandi berbayar. Pemandian umum. Pemandian umum.'

Pada data di atas, kata oyuya disepadankan menjadi pemandian. Data terjemahan tersebut dapat dikatakan mencapai kesepadanan karena memiliki makna yang sama, yaitu tempat untuk mandi. Dalam terjemahan tersebut tidak memuat kata 'umum' hanya 'pemandian' saja karena konteks dalam tuturan tersebut menyatakan “jutaan jin datang ke pemandian ini....”, kata 'jutaan jin' dapat menjadi penjelasan jika pemandian tersebut digunakan untuk umum.

Prosedur penerjemahan yang diterapkan adalah netralisasi, yaitu menerjemahkan kata BSu ke dalam BSa dengan memilih kata yang lebih netral dan bebas dari unsur 
budaya (Newmark, 1988:83). Dalam kebudayaan BSa, pemandian umum biasanya terdapat pada area terbuka dan jarang ditemui seperti konsep pemandian umum dalam kebudayaan BSu yang terletak di dalam suatu ruangan atau bangunan. Oleh karena itu, penerjemah memilih padanan kata yang bebas dari unsur budaya karena sulit untuk menemukan padanan kata sesuai makna BSu. Kata pemandian dirasa mampu untuk memberikan gambaran umum kepada pembaca $\mathrm{BSa}$ mengenai makna yang ingin disampaikan BSu.

\section{d. Kombinasi}

(4) $\mathrm{BSu}$ : 風呂釜にこき使われとる爺だ。

Furogama ni kokitsukawaretoru jijida.

$\mathrm{BSa}$ : Budak ketel untuk memanaskan air pemandian.

(Sen to Chihiro no Kamikakushi, 00.25.04 - 00.25.08)

Dalam dictionary.goo.ne.jp, pengertian furogama adalah: 据風呂のたき口の部分。

'Bagian tungku pembakaran dalam suefuro (bak mandi dengan tangki pemanas air).'

Pada data di atas, kata furogama diterjemahkan menjadi ketel untuk memanaskan air pemandian. Dalam KBBI daring, pengertian ketel adalah cerek, kuali besi sebagai penanak nasi, tangki pemanas air yang digunakan untuk menggerakkan mesin.

Penerjemah menambahkan beberapa kata setelah kata ketel untuk menjelaskan ketel yang dimaksud dalam BSu, dengan tujuan agar pembaca BSa tidak salah mengartikan kata ketel yang umumnya dimaknai sebagai cerek. Berdasarkan pengertian furogama dan ketel di atas, maka penerjemahan tersebut dapat dikatakan mencapai kesepadanan karena makna yang dihasilkan masih sama, yaitu tangki pemanas air.

Prosedur penerjemahan yang diterapkan dalam menerjemahkan kata tersebut adalah kombinasi dari penjelasan tambahan, transposisi, dan ekspansi. Penjelasan tambahan adalah prosedur penerjemahan yang memberikan tambahan penjelasan sebagai klarifikasi mengenai kata yang dianggap asing sehingga pembaca dapat memahami makna kata tersebut (Newmark, 1988:90). Prosedur penjelasan tambahan diterapkan agar tidak terjadi kesalahpahaman oleh pembaca BSa terkait ketel yang dimaksud, sehingga penerjemah memilih untuk menambahkan beberapa kata untuk menjelaskan ketel yang dimaksud dalam BSa. 
Penambahan kata yang dilakukan penerjemah dalam menerjemahkan data di atas menyebabkan diterapkannya juga prosedur transposisi, yaitu dengan mengubah struktur kalimat agar diperoleh terjemahan yang betul (Newmark, 1988:85). Terjadi perubahan struktur kata, yang dalam BSa terdiri dari satu kata yaitu nomina, menjadi frasa nomina yang terdiri dari lima kata. Perubahan tersebut juga menyebabkan diterapkannya prosedur ekspansi, yaitu dengan menambahkan beberapa kata dalam menerjemahkan kata BSu agar tercapainya kesepadanan makna (Newmark, 1988:90).

\subsection{Terjemahan Tidak Sepadan}

\section{a. Modulasi}

(5) $\mathrm{BSu}$ : おばあちゃん、やっぱり帰る。 Obaachan, yappari kaeru.

BSa : Zeniba, aku mau kembali.

(Sen to Chihiro no Kamikakushi, 01.50.41 - 01.50.42)

Kata obaachan berasal dari kata obaasan. Dalam dictionary.goo.ne.jp, chan merupakan perubahan bunyi dari sufiks san yang digunakan untuk memanggil nama seseorang dalam situasi yang akrab. Pengertian obaasan dalam dictionary.goo.ne.jp adalah:

老年の女性を親しみ、また敬っていう語。

'Kata yang digunakan untuk memanggil wanita lanjut usia dalam suasana akrab, serta untuk menghormatinya.'

Berdasarkan pengertian di atas, maka kata obaachan dapat dimaknai sebagai panggilan untuk wanita lanjut usia dalam konteks pembicara sudah sangat dekat atau akrab dengan lawan bicaranya.

Pada data di atas kata obaachan disepadankan menjadi Zeniba, yaitu nama dari wanita yang dimaksud pembicara. Penerjemah tidak menerjemahkan kata obaachan ke dalam BSa, tetapi menggunakan nama aslinya yang justru akan terkesan tidak sopan bagi pembaca BSa. Hal tersebut disebabkan karena dalam kebudayaan masyarakat BSa memanggil seseorang yang lebih tua, apalagi lanjut usia hanya dengan menyebut namanya, akan dianggap tidak sopan. Oleh karena itu, penerjemahan kata obaachan menjadi Zeniba dapat dikatakan tidak mencapai kesepadanan karena tidak mampu menyampaikan makna kata BSu. Menurut Matsuura (1994:746), kata obaachan dapat 
dimaknai sebagai oma atau nenek dalam bahasa Indonesia. Penerjemah dapat menggunakan kata nenek atau Nek Zeniba agar pembaca BSa dapat memahami makna kata tersebut dan menghindari kesan yang tidak sopan.

Prosedur penerjemahan yang diterapkan dalam menerjemahkan kata tersebut adalah modulasi, yaitu pergeseran makna yang terjadi akibat adanya perubahan sudut pandang atau perspektif maupun dari segi lainnya, namun tidak mengubah pesan atau maksud Bsu (Newmark, 1988:88). Prosedur modulasi diterapkan dengan terjadinya penyempitan cakupan makna pada kata BSa, yang awalnya dalam BSu adalah merupakan pronomina persona kedua menjadi nama orang yang dimaksud. Penerapan prosedur ini menyebabkan terjadinya pergeseran makna sehingga dapat membuat pembaca BSa tidak memahami maksud dari kata BSu yang sebenarnya.

\section{b. Reduksi}

(6) $\mathrm{BSu}:$ あの、釜爺さんですか。 Ano, Kamaji-san desuka?

BSa : Apa kau Kamaji?

(Sen to Chihiro no Kamikakushi, 00.24.37-00.24.39)

Selain sama, san juga merupakan salah satu akhiran dalam bahasa Jepang. Dalam dictionary.goo.ne.jp, pengertian san adalah:

人名や人を表わす語に添えて、敬意を表わす語。

'Kata untuk menghormati seseorang yang melekat pada nama seseorang atau yang mewakili seseorang.'

Pengertian san di atas hampir sama dengan pengertian sama, yaitu kata yang digunakan untuk menghormati seseorang dalam bahasa Jepang. Namun dalam dictionary.goo.ne.jp, terdapat perbedaan antara penggunaan san dan sama, yaitu sebagai berikut:

「さん」は、「様」の転。「様」よりくだけた言い方で、親しみの気持ちをこ めて使う。

'San merupakan transisi dari sama. San digunakan dalam situasi yang lebih akrab dan tidak terlalu formal dibandingkan sama.'

Berdasarkan pengertian di atas, maka kata san dan sama memiliki perbedaan terkait konteks penggunaannya yang harus memperhatikan siapa lawan bicaranya. San 
digunakan pada situasi yang cenderung tidak terlalu formal sedangkan sama digunakan pada situasi yang formal. Dalam terjemahan di atas, kata Kamaji-san hanya diterjemahkan menjadi Kamaji. Hal ini dikarenakan dalam BSa tidak mengenal adanya akhiran ketika menyebutkan nama seseorang seperti dalam bahasa Jepang.

Dalam anime tersebut, Kamaji merupakan seorang pekerja di pemandian umum arwah yang sudah berumur. Dalam data di atas, sebutan Kamaji-san diucapkan oleh anak kecil bernama Chihiro. Jika dilihat dari segi umur antara Chihiro dan Kamaji yang cukup jauh, kata Kamaji-san diterjemahkan menjadi Kamaji saja akan menimbulkan kesan yang tidak sopan dan tidak dapat menyampaikan makna dari BSa ke dalam BSu, sehingga penerjemahan tersebut dikatakan tidak mencapai kesepadanan. Kata Kamaji-san dapat diterjemahkan menjadi Pak Kamaji, sehingga akan menimbulkan kesan yang lebih sopan dan dapat mewakili makna san dalam BSa.

Dalam data di atas prosedur penerjemahan yang diterapkan adalah reduksi, yaitu dengan menghilangkan unsur yang terdapat dalam BSu pada BSa (Newmark, 1988:90). Pada data di atas, reduksi diterapkan dengan menghilangkan makna san pada kata Kamaji-san. Penerjemah mungkin tidak mendapatkan padanan san dalam BSa sehingga memilih untuk menghilangkan makna sufiks tersebut dalam BSa. Namun hal tersebut akan berdampak pada pembaca BSa yang tidak memahami maksud dari kata BSu seutuhnya karena terdapat makna yang dihilangkan.

\section{Simpulan}

Berdasarkan hasil analisis kesepadanan dan prosedur penerjemahan dalam penerjemahan kosakata bermuatan budaya Jepang pada anime Sen to Chihiro no Kamikakushi ke dalam bahasa Indonesia diperoleh 2 kesimpulan sebagai berikut: Penerjemahan kosakata bermuatan budaya pada anime Sen to Chihiro no Kamikakushi sebagian besar sudah mencapai kesepadanan. Dari 38 data terjemahan, terdapat 30 data telah mencapai kesepadanan dan 8 data tidak mencapai kesepadanan.

Terdapat 7 prosedur penerjemahan yang diterapkan dalam menerjemahkan kosakata bermuatan budaya pada anime Sen to Chihiro no Kamikakushi, yaitu padanan budaya, sinonim, netralisasi, penjelasan tambahan, modulasi, transposisi, dan reduksi dan ekspansi. Padanan budaya dan sinonim menjadi prosedur penerjemahan yang paling banyak diterapkan. Hal ini disebabkan banyak kata dalam BSu tidak memiliki padanan 
dengan unsur yang spesifik dalam kebudayaan BSa, sehingga penerjemah memilih kata yang dirasa paling dekat dengan kebudayaan BSa ataupun memiliki unsur kesamaan atau bersinonim dengan kata BSa.

\section{Daftar Pustaka}

Catford, J.C. 1965. Linguistic Theory of Translation. London: Oxford University Press. KBBI, 2016. Kamus Besar Bahasa Indonesia (KBBI). Tersedia pada http://kbbi.web.id

Matsumura, A. 2021. Kokugo Jiten: Dejitaru Daijisen. Shogakukan. Tersedia pada http://dictionary.goo.ne.jp

Muryati S. dan B. S. Astuti. 2020. Penggunaan Strategi Penerjemahan Kosakata Budaya Jawa Tengah Berbahasa Indonesia ke dalam Bahasa Jepang dalam Media Informasi Pariwisata. Culture, Volume 7, Nomor 2, (hlm.204-210).

Newmark, P. 1988. A Textbook of Translation. New York: Prentice Hall.

Nida, E. A. dan C. R. Taber. 1974. The Theory and Practice of Translation. Leiden: E.J. Brill.

Prabawati, Putu, dkk. 2015. Analisis Penerjemahan Istilah Budaya pada Novel Negeri 5 Menara ke dalam Bahasa Inggris: Kajian Deskriptif Berorientasi Teori Newmark. Jurnal Ilmu Sosial dan Humaniora. Volume 3, Nomor 2, (hlm. 435-445).

Zulkarnaein, Z. 2018. Penerjemahan Kesepadanan Kosakata Fisik Bermuatan Budaya Materiil Bahasa Jepang Ke Bahasa Indonesia Dalam Novel Oda Nobunaga. Skripsi. Fakultas Ilmu Budaya. Universitas Diponegoro. 